Article

\title{
Optimization Method of Abrasive Water Jet Cutting of Welded Overlay Materials
}

\author{
Sorin Adrian Barabas * and Adriana Florescu \\ Faculty of Technological Engineering and Industrial Management, Transilvania University of Brasov, \\ 500036 Brasov, Romania; fota.a@unitbv.ro \\ * Correspondence: sorin.barabas@unitbv.ro; Tel.: +40-765-504-182
}

Received: 22 July 2019; Accepted: 24 September 2019; Published: 26 September 2019

\begin{abstract}
The great advantages of abrasive water jet cutting (AWJC) led to a rapid development of technology. The necessity of studying the process for different materials with weld overlay layers appeared due to the more widespread use of the process of jet cutting. Also, weld overlay is used widely in order to increase the durability of products used in the automotive industry. The complexity of shape, surface integrity, rapid processing, easy programming, low costs, and large flexibility of AWJC technology depends on the optimization of functional parameters and correct setting of machinability of cutting materials is one of the most important. A method of optimizing the process is the correct identification of machinability of welded workpieces with different hardness in layers. This research presents the new method and the experiments that validate the theoretical modeling. Average difference between the theoretical and the experimental values of machinability is small and lead to accuracy of results and demonstrates that this method can be used in practice.
\end{abstract}

Keywords: abrasive water jet cutting; machinability; weld overlay

\section{Introduction}

Abrasive water jet cutting (AWJC) is one of the unconventional machining processes that offers an alternative to other cutting technologies, finding its efficiency in high-precision machining of diverse and difficult-to-cut materials [1-3]. At the same time, it can also cut soft and flexible materials such as foam [4]. A great advantage of this process is given by the fact that the processed material is not subjected to thermal loads and thus does not change the structure of the material. Further, the abrasive water jet cutting process offers the possibility of processing materials in ecological conditions for sustainable development. At present, there is a major concern in the development of unconventional processing technologies in order to eliminate deficiencies associated with unconventional processing [5-8].

Current research in the field of abrasive water jet cutting demonstrates the suitable use of a very thin waterjet stream for cutting high-performance materials. With the development of the aerospace and automotive industry, the abrasive water jet cutting process is introduced into various industrial applications to process complex and high-precision structures, such as hybrid composite materials [9], glass fiber reinforced with carbon fiber (CFRP) [10,11], titanium alloys [3,12], etc.

In the current literature, there are presented some recent experimental and theoretical approaches relevant to the abrasive water jet cutting, developed mainly in the last few years [13-15]. The paper [13] presents additions on the technological advantages of the process used in various industrial applications and on the type of abrasive water jet machines. An analysis of the principle and mechanisms of material removal is also carried out, studying the influence of the setting parameters of the abrasive water jet cutting. By experimenting with the hydro abrasive water jet processing of several groups of plate-laminated materials, a technique for diagnosing and determining the machinability index was developed [14]. 
Optimizing the abrasive water jet cutting process is essential to increase productivity and economic efficiency. At present, scientific research is directed toward the study and analysis of this process by optimizing process parameters [16], modeling, and simulation [7,17]. Research conducted in [18] involves the theoretical modeling and numerical simulation of particle velocity fields in micro abrasive jet processing. Depending on the diversity of materials and their degree of machinability, many cutting strategies can be analyzed and implemented $[19,20]$.

The efficient use of the abrasive water jet cutting process involves analyzing the impact of process parameters on performance indicators such as cutting quality, productivity, and costs [6]. The analysis and prediction of the surface roughness of processed materials with abrasive water jet were studied in [21-23]. By applying some empirical mathematical models, the influence of the parameters of the abrasive water jet process (average size of the abrasive particles, distance between the nozzle and the surface of the test piece and the angle of impact) on the roughness of the experimentally processed surface has been highlighted [24]. An advanced tool used in [25] for predicting surface roughness parameters in abrasive water jet cutting processing (AWJC) is neural network modeling.

Besides the usual abrasive water jet cutting operations of various materials [26], the process can also be used for polishing and cleaning surfaces [27] with an abrasive water jet. The paper [28] develops a methodology for using the abrasive water jet machine and the surface treatment for welded joints. The optimization of processing parameters-jet pressure, standoff distance, nozzle geometry, traverse speed, and type of abrasive-is considered. By applying the abrasive water jet wash process, the residual stresses of the treated surface are significantly improved. The main advantages over the application of other conventional processes, such as "scrubbing, laser polishing," are to increase flexibility in machining and ecological surface treatment. An important study on the surface integrity analysis of abrasive water jet-cut surfaces of friction stir welded joints [29] demonstrates that "unlike other conventional or unconventional processes, no heat-affected minimum zone (HAZ) is generated during friction stir welded (FSW) by using abrasive water jet technology." An experimental analysis was performed by processing the FSW joints, determining the roughness of these surfaces, and using an optical 3D measuring system.

The diversity of processed material by abrasive waterjet—mild steels, alloy steels, tool steels, titanium alloys, aluminum, ceramics, marble, and glass-has a common feature, namely, constant machinability on the entire processed surface. This allowed manufacturers of water jet machinery to provide easy configurations for cutting process that take into account two factors-depth of cut and machinability.

Some reference values of material machinability for a limited number of materials are already available [30-32], but in the case of materials that have different machinability over the processed surface-thermochemical treated materials, multilayers work pieces, weld overlay work pieces-these values do not exist. This research aims to establish a link between machinability and thickness of the layers and give a computing solution for optimal machinability and experimental validation of the proposed solution. Is necessary to estimate new values of parameters for the system processing for finding an optimum solution.

The main parameters that determine the quality and precision of the abrasive water jet machine are cutting depth, pressure and velocity of the jet, and type of abrasive used. In addition, the property that greatly influences the appearance of the surface processed by AWJ technology is the machinability of the material $[33,34]$. In the literature, there are several definitions for machinability, the representative being the one stated in [32]: "Machinability is a quantified kinetic response of a workpiece material subjected to a certain machining operation and condition." As a result, the machinability is influenced by other factors like hardness, microstructure of the material, and technological development, so the optimal value can be determined relative to a standard value.

Because manufacturing of materials is different for every type of operation, companies that produce cutting equipment define their own standards for processed material. In the case of cutting with abrasive jet, depending on the equipment and software used, some of these packages of machining 
values include Omax, Flow, Mitsubishi, etc. The need to create a database to encompass the scale of machinability for different topologies, material groups, and different types of machines becomes absolutely necessary. The emergence of new material types means this database will be constantly added to.

The cutting of welded, thermochemical treated, or multilayer material shows problems in establishing the correct machining, with direct consequences on the cutting process. Incomplete cutting resulting in scrap-or the reverse, a too strong cut with high consumption of abrasive and energy, leading to a much too long machining time and to an unprofitable cost price-are the direct effects of not knowing machining of some types of parts that need to be cut. For the user of this sort of machine, the losses become significant, so the completion of the database becomes absolutely necessary. In this purpose, the present paper proposes a new algorithm of calculation that allows the rapid determination of weld overlay material machinability with different hardness. Mathematical modeling is based on knowing the machinability and thickness of every layer, so the algorithm allows us to obtain an optimal value of machinability for the entire material.

The difference of hardness in the layers can create significant problems $[35,36]$ manifested by incomplete cutting when choosing a too large machinability and raising the cost of processing when choosing a too small machinability. On a Maxiem 1530 waterjet cutting machine, a decrease of machinability by $20 \%$ leads to an increase in processing time by about $25 \%$ while the consumption of the abrasive to cut a piece of tool steel RC20 with a thickness of $30 \mathrm{~mm}$ over a length of $100 \mathrm{~mm}$ is $23 \%$ higher [37]. Material thickness and its machinability have a direct effect on the setting of the traverse speed jet. The traverse speed of the jet is the factor that determines the quality of the piece obtained, with a high speed leading to the appearance of striations and roughness due to the loss of kinetic energy of particles in the cutting process, and in extreme cases to incomplete cuts, while a too low speed causes economic losses [38,39].

Given that the thickness of the layers with different hardness is easily measured and their hardness is known, the problem is to determine an intermediate machinability to satisfy the requirement conditions of quality and to correspond from economic terms. Another parameter of Omax software, Intelli-Max Layout (version 30, Omax Corporation, South Kent, WA, USA) is the surface finish quality, defined in five levels Q1-Q5, where Q1 represents the configuration for the best surface quality and Q5 represents the configuration for the lowest quality surface. In this paper, Q3 was considered the medium level or the base quality. A linear modeling method was used to find a theoretical solution, and a proximity method was used by comparing specific hardness. For experimental work, Q3 was chosen as the standard roughness for the reference model.

So far, from what has been investigated, abrasive jet cutting has not been optimized for weld overlay work pieces with different hardness on the machined surface. These studies are therefore new and improve the processing of welded materials.

Weld overlaying is characterized by the deposition of a filler metal on a base metal to improve its properties [40]. Metals covered through the welding method show distinct advantages, especially when they work in difficult conditions. The material used for cover is generally a wear-resistant material, featuring high hardness. The type of electrode used for plating determines the properties of the workpiece, contributing to raising the quality of functioning [41].

One of the problems that arise in relation to workpieces covered by welding pieces is their machinability. The appearance of layers with different hardness makes further processing (cutting, milling, drilling, etc.) difficult. The three hardness zones-base material (BM), the heated affected zone (HAZ), and the weld overlay zone (WOZ) - a weld-plated piece have different values for machinability depending on the material used in plating, the welding method, and the geometric parameters of the covering [42-45]. 


\section{Materials and Methods}

Optimization of the cutting process of welded covered pieces by abrasive water jet must consider the existence of three different hardness zones, each having a known machinability and a known thickness. In the abrasive jet cutting process, cutting is produced by removing part of the material that comes in contact with the abrasive particles and is influenced by the hardness of the removed material. Measuring the hardness and thickness of layers of the material and making a direct connection between machinability and the hardness can approximate the machinability values of the layers. The present research aims to verify and validate this hypothesis, allowing for the optimization of jet cutting of workpieces covered by welding.

\subsection{Weld Overlay}

The cover welding process is characterized by the appearance of three hardness zones in the work piece (Figure 1) with different microstructures-the basic area, the superheated area, and zone filed by welding. The research aims to optimize abrasive jet cutting of materials coated with the metal of greater hardness in order to increase wear resistance. The process of the melt material deposition occurs after the following fundamental Equations [1].

$$
E=\frac{\eta_{e} P_{c}}{V_{e}}=\frac{\eta_{e}\left(P_{e}+P_{a}\right)}{V_{e}}=\frac{\eta_{e} I\left(u_{e}+u_{a}\right)}{V_{e}}
$$

where $E$ is linear power utilized in welding process $(\mathrm{j} / \mathrm{m}), \eta_{\mathrm{e}}$ is efficiency of the power transfer, $P_{c}$ is electrical power of process $(\mathrm{W}), P_{e}$ is power drop on electrode out $(\mathrm{W}), P_{a}$ is power of electric arc $(\mathrm{w})$, $I$ is arc current $(\mathrm{A}), u_{e}$ is voltage drop of electrode out $(\mathrm{V}), u_{a}$ is voltage of electric arc $(\mathrm{V})$, and $V_{e}$ is speed of welding $(\mathrm{m} / \mathrm{s})$.

$$
\begin{gathered}
t_{w}=\frac{m_{w}}{\alpha_{w} I}=\frac{A_{w} L_{w} \rho}{\alpha_{w} I}, \\
V e=\frac{L_{w}}{t_{w}}=\frac{\alpha_{w} I}{A_{w} \rho},
\end{gathered}
$$

where

$t_{w}$ is time of welding (s);

$m_{w}$ is mass of welded zone $(\mathrm{Kg})$;

$\alpha_{w}$ is a deposition coefficient of welded material;

$A_{w}$ is aria of deposition $\left(\mathrm{mm}^{-2}\right)$;

$L_{w}$ is length of welding $(\mathrm{mm})$ and $\rho$ is electrode material density.

From (1) and (3), the result is

$$
A_{w}=\frac{\alpha_{w} E}{\eta_{e} \rho\left(u_{e}+u_{a}\right)}
$$

Equation (4) shows the dependence of area of deposited material by type of electrode material $\left(\alpha_{w}\right)$ and the characteristics of electricity, which operates the welding process. The starting of melting is achieved at the contact between the special tube and the material by the formation of an electric arc. The distance of this to the base material continues the process by ion transfer from the electrode to the workpiece material, which maintains arc transfer and melts the electrode. The droplets are deposited on the base material, and heat is transfer to it from an overheated area and favors chemical reactions that change the structure and properties in the area and thus there hardness. 


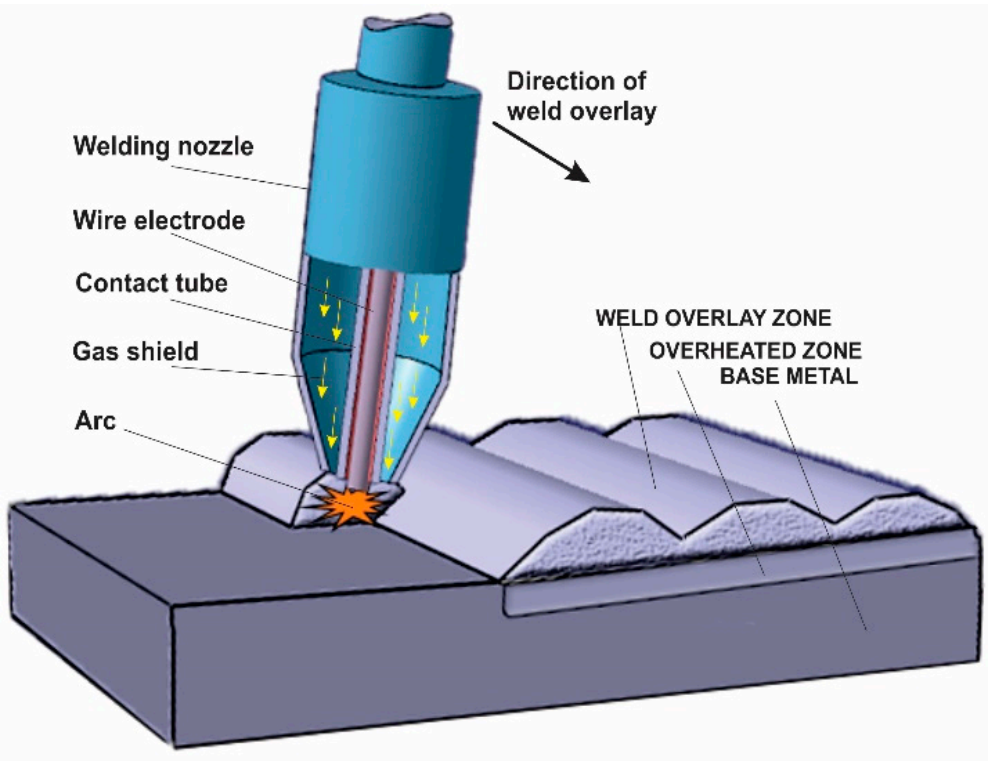

Figure 1. Weld overlay scheme.

\subsection{Abrasive Waterjet Cutting}

The properties of a finite work piece processed by abrasive waterjet cutting is influenced by two major factors: material properties and abrasive waterjet properties [46]. Optimization of these factors leads to new parameters of cutting and to a better finite product. Figure 2 presents the position and influence of material machinability to the finite product.

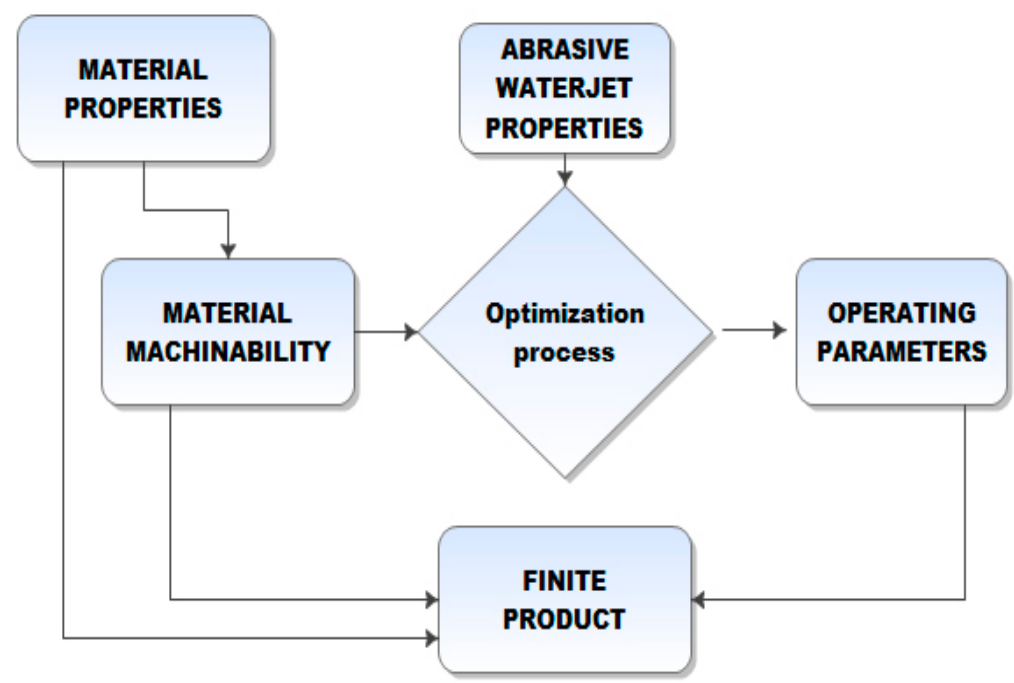

Figure 2. Water jet cutting process.

The traverse speed $\left(V_{t}\right)$ of the abrasive jet has a greater impact on the optimal configuration of the abrasive water jet cutting process [35]

$$
V_{t}=\frac{W_{r}}{d_{n} H_{c}}
$$

where $V_{t}$ is traverse speed of abrasive jet $(\mathrm{mm} / \mathrm{s}), W_{r}$ is the rate of removal unit volume of material $\left(\mathrm{mm}^{3} / \mathrm{s}\right), d_{n}$ is the nozzle bore diameter $(\mathrm{mm})$, and $H_{c}$ is thickness of material $(\mathrm{mm})$ [37]

$$
W_{r}=\frac{1}{2} I_{m} V_{j}^{2} M_{s}
$$


where $I_{m}$ is impulse given to the abrasive mixture in unit time $(\mathrm{g} \mathrm{m} / \mathrm{s}), V_{j}$ is abrasive jet velocity at the exit of the nozzle $(\mathrm{m} / \mathrm{s})$, and $M_{S}$ is specific machinability of material.

$$
V_{j}=\mu \xi \sqrt{\frac{2 p}{\rho_{f}}}
$$

where $\mu$ is the acceleration coefficient of the orifice ring for high speed; $\xi$ is a coefficient that takes into account the characteristics of abrasive, grinding, friability, and inhomogenities; $p$ is the pressure of the liquid in the mixing tube (MPa); and $\rho_{f}$ is the density of the abrasive fluid $\left(\mathrm{g} / \mathrm{mm}^{-3}\right)$.

According Equations (5) and (6), traverse speed $\left(V_{t}\right)$ is inversely proportional with thickness $\left(H_{c}\right)$ and directly proportional with specific machinability $\left(M_{S}\right)$.

\subsubsection{Determination of Machinability of Cutting Materials}

For determining the machinability of a weld overlay workpiece, known hardness in the layers (BM, HAZ, and WOZ) must be considered. Machinability is approximated according to the schedule of maximum and minimum values. The graph in Figure 3 is made with OMAX values of machinability (Table 1). Tests for each material were made to measure their hardness and carbon composition. Machinability is approximated according to the diagram of maximum and minimum values.

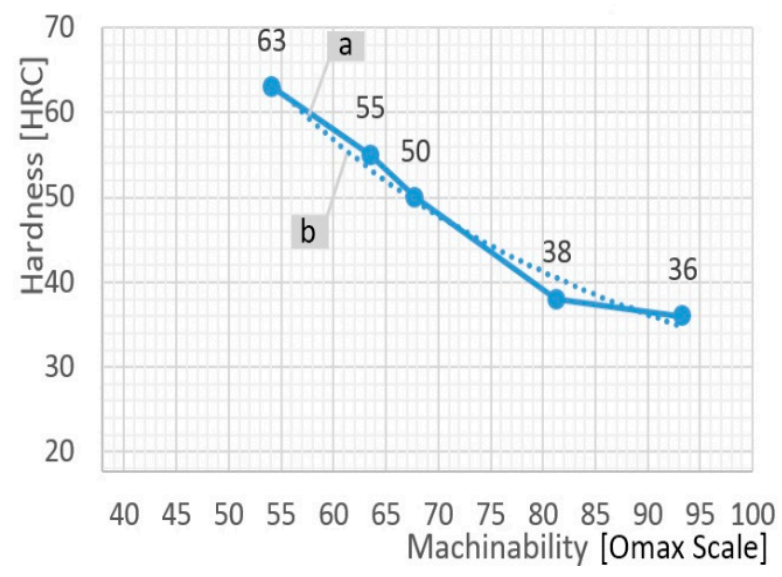

Figure 3. The relation between hardness and machinability for steel materials (a) graph resulted from assignation of value presented in Table 1 ; (b) logarithmic curve approximated after the value presented in Table 1.

Table 1. The machinability, hardness and carbon composition.

\begin{tabular}{ccccc}
\hline Material & $\begin{array}{c}\text { Machinability } \\
\text { (Omax) }\end{array}$ & $\begin{array}{c}\text { Hardness } \\
\text { (HRC) }\end{array}$ & \%C & Heat Treatment \\
\hline Tool Steel D2 RC60 & 54.08 & 62 & 1.48 & hardened \\
Tool Steel D2 RC50 & 63.51 & 55 & 1.41 & hardened \\
Stainless Steel 4340 & 80.80 & 50 & 0.39 & hardened \\
Mild Steel A36 & 81.30 & 38 & 0.26 & annealed \\
Invar 36 & 93.3 & 36 & 0.14 & annealed \\
\hline
\end{tabular}

The machine values presented in Table 1 and used in the construction of the diagram in Figure 3 are the values used by the company Omax, in the Intelli-Max software installed on the Maxiem 1530 jet cutting machine (Omax Corporation, South Kent, WA, USA). A link between machinability Omax and Flow is presented in the scientific paper [32]. Values of hardness and chemical composition were measured on test samples. In assessing the link between hardness and machinability, in the case 
of metal alloys, the following was approximated (Figure 3): the curve (a) of measured values was generalized to the logarithmic form (b).

The percentage of carbon in the material and the type of heat treatment applied are two factors that influence the machinability of the material by changing its hardness.

This graph allows us to choose values for the machinability and function of hardness for any type of alloy steel. For approximation, the logarithmic curve is considered.

\subsubsection{Machinability Computation for Weld Overlay Materials}

An important influence on the development of processing the welded overlay materials on the abrasive water jet machine is the characteristic of machinability (M). In the case of those materials covered by welding, the machinability has different values for each layer due to the multilayer characteristics. However, abrasive jet cutting machines allow for the insertion of a single value for machinability. Currently, there is no method for establishing the necessary machinability in cutting a multilayer material using the machinability of the rough layer. Considering that the material still has two layers with better machinability, it is obvious that a method for calculating the optimum resulted machinability leads to an increase of the traverse speed, thus optimizing the whole process.

In order to determine the optimal machinability, a calculation model has been proposed. The mathematical model for computation of weld overlay materials takes into account the three layers with different hardness: weld overlay zone WOZ (thickness-a), heated affected zone HAZ (thickness-b), and base material zone BM (thickness-c). The coating layered by welding is used to increase the wear resistance of the material and has a higher hardness and, consequently, a lower machinability. The overheated layer (HAZ) with a macinability of $\mathrm{M}_{2}$ presents the qualities of a heat-treated material with a higher hardness than the base material (BM) with a machinability of $\mathrm{M}_{1}$ but smaller than the hardness of coating layer (WOZ) with a machinability of $\mathrm{M}_{3}$.

Thus, the optimum value of the machinability is established by taking into account of the machinability values known for every layer $\left(M_{1}, M_{2}\right.$, and $\left.M_{3}\right)$ with the next property $\left(M_{1}>M_{2}>M_{3}\right)$ and with a thickness of $c, b$, a. The first two machinable layers, with a machinability of $M_{1}(B M)$ and $\mathrm{M}_{2}$ (HAZ), have an intermediate resultant machinability of $M_{R(\mathrm{i})}$ (Figure 4).

$$
M_{R(i)}=M_{1}-\left(M_{1}-M_{2}\right) \frac{b}{b+c},
$$

For $c=0, b /(b+c)=1: M_{R(i)}=M_{1}$

For $c$ incline to very big values: $b /(b+c)$ incline to $0: M_{R(i)}=M_{2}$

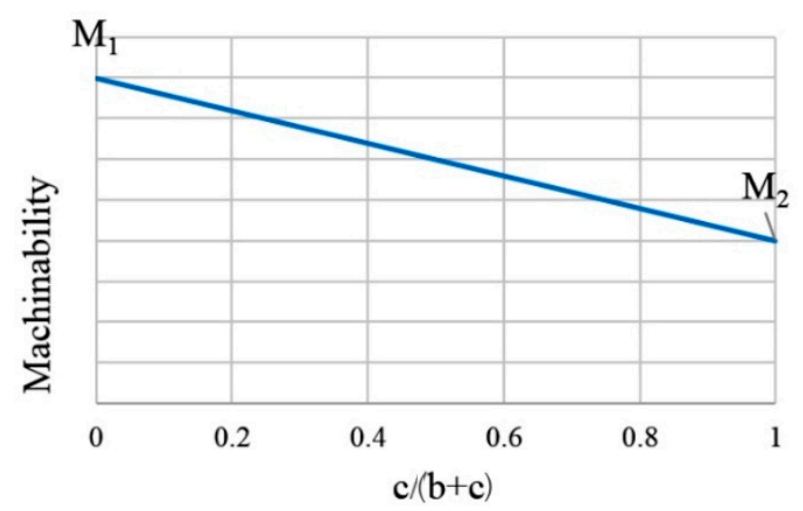

Figure 4. Machinability distribution function thickness of layers (1 is the base material (BM) zone, and 2 is the overheated layer (HAZ) zone). 
The theoretic machinability of the entire workpiece $M_{R(f)}$ depends on the machinability of all layers $\left(\mathrm{M}_{3}\right.$ is the machinability of the welded zone) and their thickness (Figure 5).

$$
\begin{gathered}
M_{R(f)}=M_{R(i)}-\left(M_{R(i)}-M_{3}\right) \frac{a}{a+b+c}, \\
M_{R(f)}=M_{R(i)}-\left(M_{R(i)}-M_{3}\right) \frac{a}{H},
\end{gathered}
$$

where $\mathrm{H}$ is thickness of workpiece $(\mathrm{mm})$.

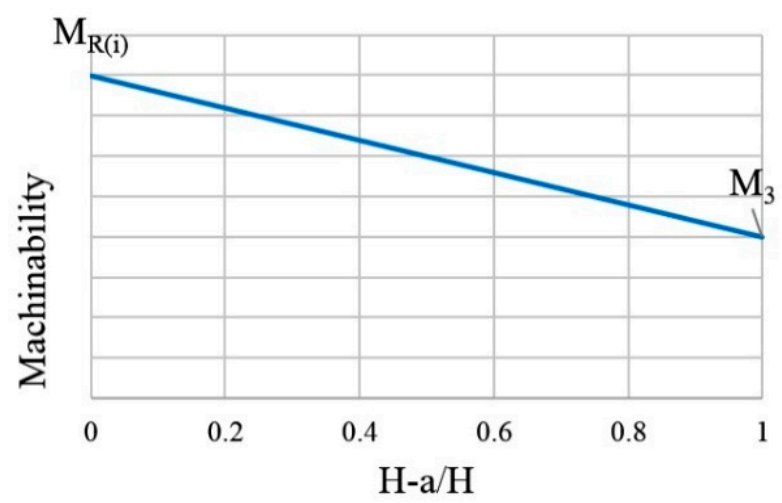

Figure 5. Machinability distribution function thickness of layers $\left(R_{(i)}\right.$ is resultant zone, and 3 is welded zone).

Following the elaboration of the optimization model, the equation for calculating the optimal machinability (Equation (10)) for the entire multi-layered piece was obtained. The dependence between the optimum machinability resulting from the calculation and the thickness of the layers of the welded material is observed. The model finds applicability in the construction of parts covered by welding that require cutting in the automotive industry, the aeronautical industry, and in the manufacture of components for wind power plants [47].

This model ensures a complete cutting, but the quality of the surface is still unknown. The value of roughness is measured after etalon (in Q3 quality level) and is considered in this study to be the optimum roughness. Experimental determinations were made using a robust design and the method of designing fractional factorial experiments [48].

\section{Experiments and Discussions}

For the experiment, 10 samples were conceived: five samples were coated with cored welding wire Robodur K 600-G, $\Phi=1.6 \mathrm{~mm}$, and the other five samples were coated with welding wire FD 64, $\Phi=1.6 \mathrm{~mm}$, the layer having a thickness of $1,3,5,8$, and $10 \mathrm{~mm}$. SAE 3310 was chosen as the base material, having thickness of $10 \mathrm{~mm}$, with the following composition (Table 2):

Table 2. The chemical composition of used steel.

\begin{tabular}{lccccccc}
\hline & \multicolumn{8}{c}{ Chemical Composition (\%) } \\
\cline { 2 - 8 } Steel SAE 3310 & $\mathbf{C}$ & $\mathbf{M n}$ & $\mathbf{S i}$ & $\mathbf{C r}$ & $\mathbf{N i}$ & $\mathbf{M o}$ & $\mathbf{S}$ \\
\cline { 2 - 9 } & 0.10 & 0.52 & 0.28 & 1.44 & 3.7 & 0.17 & 0.02 \\
\hline
\end{tabular}

The welding wire material composition is presented in Table 3. 
Table 3. The chemical composition of used wire.

\begin{tabular}{ccccccc}
\hline \multirow{2}{*}{ Wire } & \multicolumn{7}{c}{ Chemical Composition (\%) } \\
\cline { 2 - 7 } & C & Mn & Si & Cr & Mo & V \\
\hline $\begin{array}{c}\text { K 600-G } \\
\text { EN 14700 T Fe2 }\end{array}$ & 0.5 & 1.23 & 0.68 & 6.20 & 0.70 & - \\
\hline $\begin{array}{c}\text { FD 64 } \\
\text { EN 14700 T Fe16 }\end{array}$ & 4.2 & 0.5 & 1.2 & 22.5 & - & 1.0 \\
\hline
\end{tabular}

The configuration of the welding process is described in Table 4.

Table 4. The chemical composition of used steel.

\begin{tabular}{cccc}
\hline $\begin{array}{c}\text { Welding current } I \\
\text { (A) }\end{array}$ & $\begin{array}{c}\text { Tension of the Arch } U \\
\text { (V) }\end{array}$ & $\begin{array}{c}\text { Type of } \\
\text { Current/Polarity }\end{array}$ & $\begin{array}{c}\text { Speed of the Wire } \\
\text { (cm/min) }\end{array}$ \\
\hline 129 & 16.4 & DC+ & 270 \\
\hline $\begin{array}{c}\text { Ascending Speed } \\
(\mathbf{c m} / \text { min) }\end{array}$ & $\begin{array}{c}\text { Oscillation } \\
\text { Amplitude } \\
(\mathbf{c m})\end{array}$ & $\begin{array}{c}\text { Oscillation Frequency } \\
(\text { (rev/min) }\end{array}$ & $\begin{array}{c}\text { Introduced Linear } \\
\text { Energy } \\
(\mathbf{K J} / \mathbf{c m})\end{array}$ \\
\hline 9.2 & 0.416 & 42 & 11.04 \\
\hline
\end{tabular}

A fine sorbite microstructure type (Figure 6) is observed in the base material. Austenite and globular pearlite (Figure 7) can be distinguished in the superheated zone. Islands of martensite in a mass of austenite (Figure 8) occur in the welding area of the coating with FD64, and hardening martensite (Figure 9) occurs in the case of welding with k 600-G.

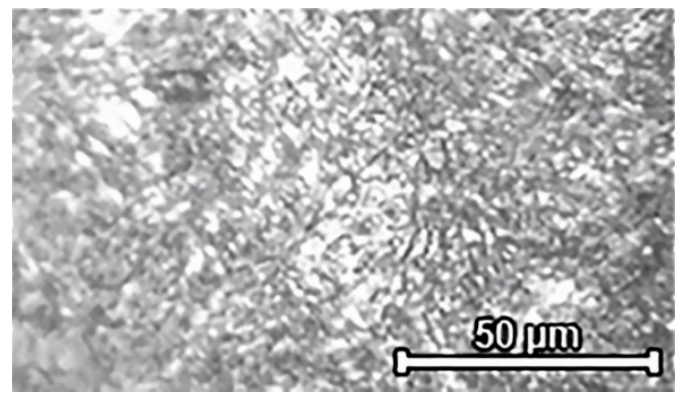

Figure 6. Microstructure in zone of fine sorbite as a base material, hardness 34 HRC.

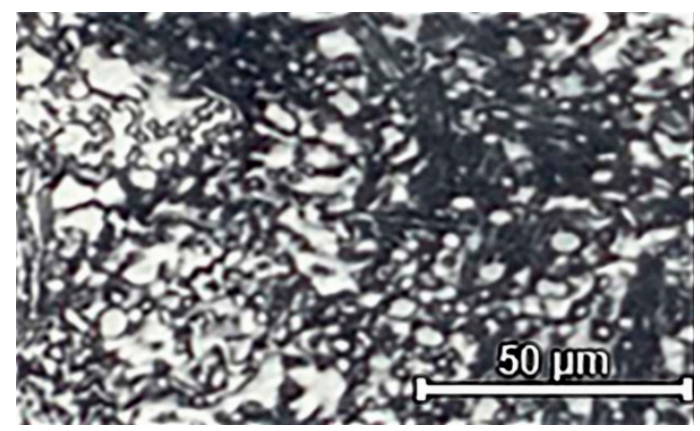

Figure 7. Microstructure in overheated zone-austenite and globular pearlite, hardness 38 HRC. Attack: nital 2\%; magnification: $100 x$. 


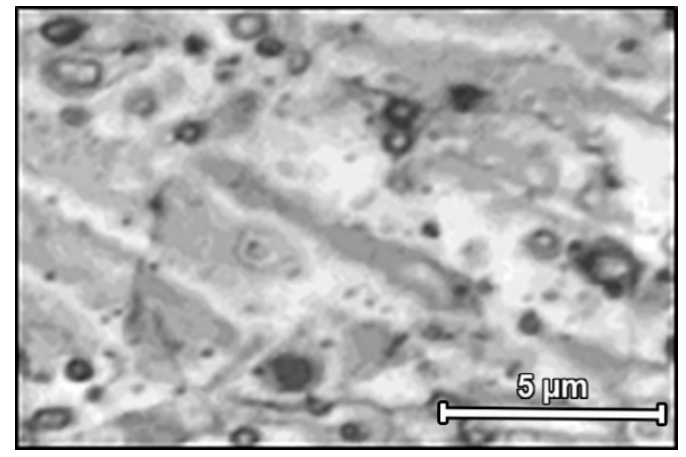

Figure 8. Microstructure in zone of welded zone for FD 64 wire-austenite and martensite islands, hardness 62 HRC. Attack: nital 2\%; magnification: 800x.

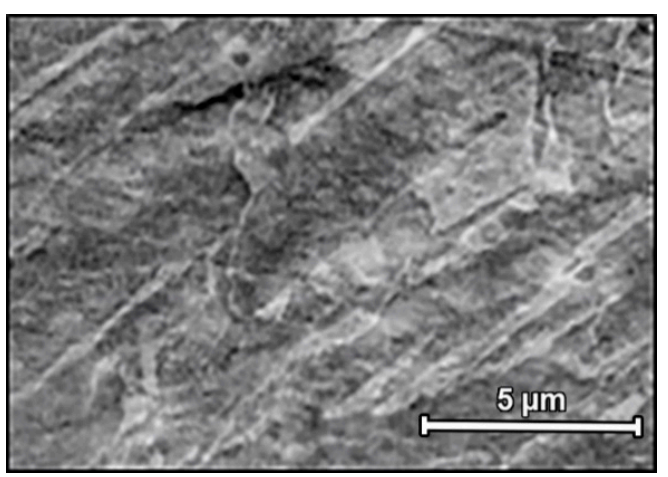

Figure 9. Microstructure in zone of welded zone for K 600-G wire-martensite, hardness 57 HRC. Attack: nital 2\%; magnification: 800x.

The hardness was measured with a Zwick device. For BM values, hardness was measured at 5 $\mathrm{mm}$ of the edge in the middle of the BM. For HAZ values, measurements were made to the limit of the $\mathrm{BM}$ zone at $10 \mathrm{~mm}$. For hardness in welding overlay zone (WOZ), measurements were made at 11, 13, 15,17 , and $19 \mathrm{~mm}$ from the edge of piece in the middle of the weld layer.

The values are presented in Table 5.

Table 5. Hardness of the samples.

\begin{tabular}{|c|c|c|c|c|c|c|c|c|}
\hline \multirow{2}{*}{\multicolumn{2}{|c|}{ Sample }} & \multicolumn{7}{|c|}{ Hardness (HRC) } \\
\hline & & BM & HAZ & WOZ 1 & WOZ 2 & WOZ 3 & WOZ 4 & WOZ 5 \\
\hline 1 & \multirow{5}{*}{ FD 64} & 33 & 38 & 58 & - & - & - & - \\
\hline 2 & & 33 & 36 & 58 & 59 & - & - & - \\
\hline 3 & & 34 & 37 & 58 & 58 & 59 & - & - \\
\hline 4 & & 34 & 36 & 58 & 59 & 60 & 62 & - \\
\hline 5 & & 32 & 38 & 57 & 58 & 60 & 62 & 62 \\
\hline 6 & \multirow{5}{*}{$\begin{array}{c}\mathrm{K} \\
600-\mathrm{G}\end{array}$} & 33 & 35 & 53 & - & - & - & - \\
\hline 7 & & 34 & 36 & 52 & 53 & - & - & - \\
\hline 8 & & 34 & 35 & 53 & 54 & 55 & - & - \\
\hline 9 & & 34 & 35 & 53 & 53 & 55 & 56 & - \\
\hline 10 & & 33 & 34 & 53 & 53 & 54 & 56 & 57 \\
\hline
\end{tabular}

Figure 10 presents the diagram of hardness for samples 5 and 10. 


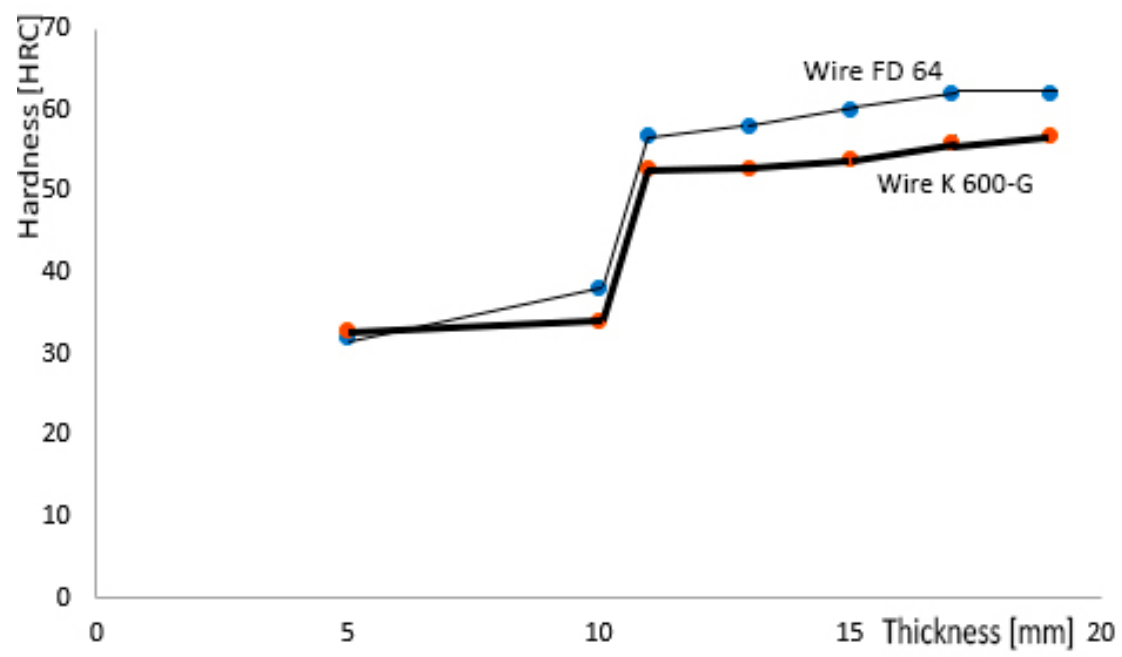

Figure 10. Hardness distribution function for the thickness of the workpiece.

The cutting piece roughness $R_{a}$ is considered optimum if the measured value corresponds with the etalon roughness $R_{\text {aopt }}$ (in the Q3 quality level). When the machinability values for $R_{a}$ measured on the samples is equal with $R_{\text {aopt }}$ measured on the etalon, those values become $M_{\text {opt }}$.

Depending on the thickness ratio of the layers with different hardness, 10 values of optimum machinability after cutting jet were obtained. The only changed factor was machinability, and the control mark was standard roughness (Figure 11).

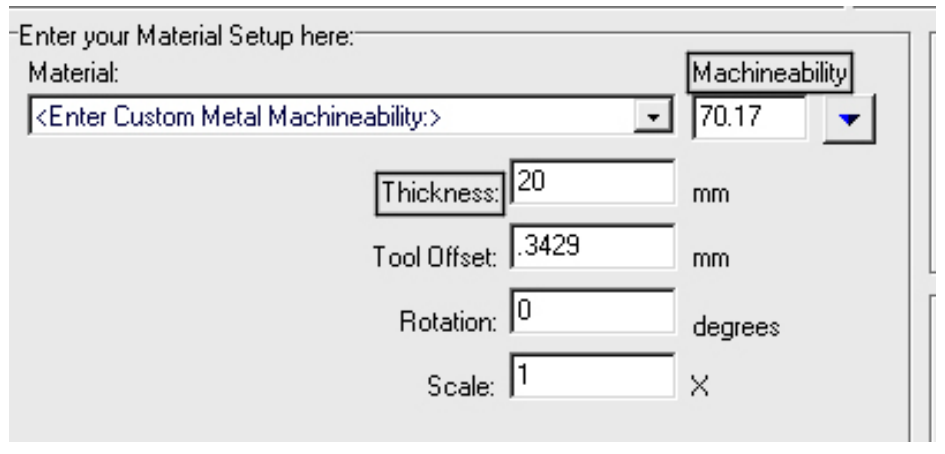

Figure 11. Maxiem 1530 setup. Machinability and thickness are main factors for the configuration of the abrasive water jet technology (AWJ) process (Intelli-Max Software).

For thickness, introduced values are very clearly measured. For machinability, every process has its own interpretation, and for materials with different hardness in its layers, this method is a solution for a mathematical computation.

The proposed method validation was achieved through successive abrasive jet cutting and then compared the theoretical machinability, mathematically achieved with optimum machinability obtained through trial. The values are recorded in Table 6.

Obtained values for each sample were compared with the theoretical value of machinability. It was observed that the experimentally values obtained are lower, with values between $6.5 \%$ and $9.2 \%$, namely, a mean value of difference of $7.67 \%$.

Samples were taken on a Maxiem 1530 (Omax Corporation, South Kent, WA, USA) abrasive jet cutting machine equipped with Intellimax software and using a pump that provides a pressure of 3450 bar. The nozzle was positioned at a fixed distance of $1 \mathrm{~mm}$ to the work piece, and the jet was perpendicular to the cutting direction. A small amount of the difference between the experimental and 
theoretical results and the positioning of these values in the sense of shrinking the traverse speed so as to obtain a full cutting allows us to draw favorable conclusions.

Table 6. Theoretical and practical values of machinability for welded samples.

\begin{tabular}{cccccc}
\hline WOZ/MB (FD 64) & $\mathbf{0 . 2}$ & $\mathbf{0 . 4}$ & $\mathbf{0 . 6}$ & $\mathbf{0 . 8}$ & $\mathbf{1 . 0}$ \\
\hline$M_{t h}$ & 121.3 & 103.1 & 89.7 & 74.9 & 60.4 \\
$M_{\text {opt }}$ & 113 & 96 & 83 & 68 & 55 \\
Difference (\%) & $6.8 \%$ & $6.9 \%$ & $7.4 \%$ & $9.2 \%$ & $8.9 \%$ \\
\hline WOZ/MB (K600-G) & $\mathbf{0 . 2}$ & $\mathbf{0 . 4}$ & $\mathbf{0 . 6}$ & $\mathbf{0 . 8}$ & $\mathbf{1 . 0}$ \\
\hline$M_{t h}$ & 110.2 & 96.5 & 82.1 & 65.8 & 57.1 \\
$M_{\text {opt }}$ & 103 & 89 & 76 & 60 & 53 \\
Difference (\%) & $6.5 \%$ & $7.7 \%$ & $7.4 \%$ & $8.8 \%$ & $7.1 \%$ \\
\hline Media of Difference & & $7.67 \%$ & & \\
\hline
\end{tabular}

\section{Conclusions}

Abrasive water jet technology (AWJ) is currently used for cutting complex material structures, providing dimensional precision and surface quality in various industrial applications. Welded overlay materials are used widely in the energy industry because of the difficult working conditions. The implementation of a method to make the processing easier is necessary. Following this study and experimental research using AWJ technology for welded overlay processing, the possibility of machining was analyzed by establishing a link between the machinability and the thickness of the layers.

The resulting theoretical machinability is better than the machinability of the layer with maximum hardness, resulting in an energy gain and less time for cutting material, thus lower the cost of the technological operation. The value obtained ensures complete material cutting and the required quality.

The proposed optimization provides a solution for optimal machinability calculation, and the experimental validation of the proposed solution was carried out on several samples. By improving the processing parameters and their control, the machining using the abrasive water jet machine has been optimized. A higher theoretical machinability than the machinability of the stratum with maximum hardness was achieved. This has led to the optimization of material cutting time, lower cost of technology, and energy gains. The value obtained ensures complete material cutting and the required quality.

For a required roughness, establishing an optimum machinability ensures maximum productivity. Experiments confirm this way to calculate the machinability for materials covered by welding. Even if a few approximations are made (such as the machinability of HAZ zone is assimilated with the machinability of the BM zone because there is only a small difference and a small thickness of HAZ between them), the experimental results show a substantial similarity to the theoretical results. Mathematical computation of machinability allowed us to achieve an optimal value for each sample.

The optimization of abrasive water jet cutting consists of increasing efficiency, increasing the traverse velocity, and decreasing the amount of abrasive garnet used. The optimization of AWJ increases dimensional precision, increases surface quality, increases the durability of the nozzle, reduces the price, and reduces abrasive consumption.

Author Contributions: All authors contributed equally to this work, and all authors have read and approved the final manuscript.

Funding: This research received no external funding.

Conflicts of Interest: The authors declare no conflict of interest. 


\section{References}

1. Xiao, G.; Yan, B.S.; Yuan, Y.L.; Shu, D. Literature Review of Jet Machining. Adv. Mater. Manuf. Technol. 2016, 693, 830-836.

2. Hashimoto, F.; Yamaguchi, H.; Krajnik, P.; Wegener, K.; Chaudhari, R.; Hoffmeister, H.W.; Kuster, F. Abrasive fine-finishing technology. CIRP Ann. Manuf. Technol. 2016, 65, 597-620. [CrossRef]

3. Perec, A. Experimental research into alternative abrasive material for the abrasive water-jet cutting of titanium. Int. J. Adv. Manuf. Technol. 2018, 97, 1529-1540. [CrossRef]

4. Burnham, C. The Ultimate Guide to Waterjet; Flow International Corporation: Kent, WA, USA, 2015. Available online: https://www.flowwaterjet.cz/FlowWaterjet/media/Flow/8_Footer/Resources/Downloads/ebooks/TheUltimate-Guide-to-Waterjet.pdf (accessed on 3 July 2019).

5. Ally, S.; Spelt, J.K.; Papini, M. Prediction of machined surface evolution in the abrasive jet micro-machining of metals. Wear 2012, 89-99, 292-293. [CrossRef]

6. Janković, P.L.; Madić, M.J.; Petković, D.L.; Radovanović, M.R. Analysis and modeling of the effects of process parameters on specific cutting energy in abrasive water jet cutting. Therm. Sci. 2018, 22 (Suppl. 5), S1459-S1470.

7. Miao, X.; Wu, M.; Qiang, Z.; Wang, Q.; Miao, X. Study on optimization of a simulation method for abrasive water jet machining. Int. J. Adv. Manuf. Technol. 2017, 93, 587-593. [CrossRef]

8. Putz, M.; Dix, M.; Morczinek, F.; Dittrich, M. Suspension Technology for Abrasive Waterjet (AWJ) Cutting of Ceramics. Procedia CIRP 2018, 77, 367-370. [CrossRef]

9. Putz, M.; Rennaua, A.; Dixa, M. High Precision Machining of Hybrid Layer Composites by Abrasive Waterjet Cutting. Procedia Manuf. 2018, 21, 583-590. [CrossRef]

10. El-Hofy, M.; Helmy, M.O.; Escobar-Palafox, G.; Kerrigan, K.; Scaife, R.; El-Hofy, H. Abrasive Water Jet Machining of Multidirectional CFRP Laminates. Procedia CIRP 2018, 68, 535-540. [CrossRef]

11. Ruiz-Garcia, R.; Mayuet Ares, P.F.; Vazquez-Martinez, J.M.; Gómez, S.J. Influence of Abrasive Water jet Parameters on the Cutting and Drilling of CFRP/UNS A97075 and UNS A97075/CFRP Stacks. Materials 2019, 12, 107. [CrossRef]

12. Chithirai, P.; Selvan, M. Selection of Process Parameters in Abrasive Waterjet Cutting of Titanium. In Proceedings of the 2nd International Conference on Emerging Trends in Engineering and Technology (ICETET'2014), London, UK, 30-31 May 2014.

13. Ruslan, M.; Fengzhou, F. Recent advances and challenges of abrasive jet machining. CIRP J. Manuf. Sci. Technol. 2018, 22, 1-20.

14. Barsukov, G.; Zhuravleva, T.; Kozhus, O. Quality of Hydroabrasive Waterjet Cutting Machinability. Procedia Eng. 2017, 206, 1034-1038. [CrossRef]

15. Haldar, B.; Ghara, T.; Ansari, R.; Das, S.; Saha, P. Abrasive jet system and its various applications in abrasive jet machining, erosion testing, shot-peening, and fast cleaning. Mater. Today Proc. 2018, 5, 13061-13068. [CrossRef]

16. Perec, A.; Pude, F.; Kaufeld, M. Obtaining the selected surface roughness by means of mathematical model based parameter optimization in abrasive waterjet cutting. Strojniski Vestnik-J. Mech. Eng. 2017, 63, 606-661. [CrossRef]

17. Gostimirovic, M.; Pucovsky, V.; Sekulic, M.; Rodic, D.; Pejic, V. Evolutionary optimization of jet lag in the abrasive water jet machining. Int. J. Adv. Manuf. Technol. 2019, 101, 3131-3141. [CrossRef]

18. Ruslan, M.; Fengzhou, F. Theoretical study on particle velocity in micro-abrasive jet machining. Powder Technol. 2019, 344, 121-132.

19. Prabhuswamy, N.R.; Srinivas, S.; Vasli, A.; Sheshashayan, M.V.; Venkatesh, S.; Roongta, Y. Machinability Studies of Aluminium 6061 cut by Abrasive Water Jet. Mater. Today Proc. 2018, 5, 2865-2870. [CrossRef]

20. Supriya, S.B.; Srinivas, S. Machinability Studies on Stainless steel by abrasive water jet-Review. Mater. Today Proc. 2018, 5, 2871-2876. [CrossRef]

21. Cojbasic, Z.; Petkovic, D.; Shamshirband, S.; Tong, C.W.; Ch, S.; Jankovic, P.; Ducic, N.; Baralic, J. Surface Roughness Prediction by Extreme Learning Machine Constructed with Abrasive Water Jet. Precis. Eng. 2016, 43, 86-92. [CrossRef] 
22. Hejjaji, A.; Zitoune, R.; Crouzeix, L.; Le Roux, S.; Collombet, F. Surface and machining induced damage characterization of abrasive water jet milled carbon/epoxy composite specimens and their impact on tensile behavior. Wear 2017, 376-377, 1356-1364. [CrossRef]

23. Klichova, D.; Klich, J. Study of the Effect of Material Machinability on Quality of Surface Created by Abrasive Water Jet. Procedia Eng. 2016, 149, 177-182. [CrossRef]

24. Slatineanu, L.; Dodun, O.; Nagît, G.; Coteaţă, M.; Tăbăcaru, L.; Beşliu-Băncescu, I. Evaluation of the surface profile obtained by abrasive jet machining. IOP Conf. Ser. Mater. Sci. Eng. 2018, 444, 032005. [CrossRef]

25. Zagorski, I.; Klonica, M.; Kulisz, M.; Łoza, K. Effect of the AWJM Method on the Machined Surface layer of AZ91D Magnesium Alloy and Simulation of Roughness parameters Using Neural Networks. Materials 2018, 11, 2111. [CrossRef] [PubMed]

26. Maros, Z. Machining of different materials with abrasive waterjet cutting. IOP Conf. Ser. Mater. Sci. Eng. 2018, 448, 012009. [CrossRef]

27. Chen, F.; Miao, X.; Tang, Y.; Yin, S. A review on recent advances in machining methods based on abrasive jet polishing (AJP). Int. J. Adv. Manuf. Technol. 2017, 90, 785-799. [CrossRef]

28. Srivastava, M.; Tripathi, R.; Hloch, S.; Chattopadhyaya, S.; Dixit, A.R. Potential of Using Water Jet Peening as a Surface Treatment Process for Welded Joints. Procedia Eng. 2016, 149, 472-480. [CrossRef]

29. Kumar, R.; Cattopadhyaya, S.; Dixit, A.R.; Bora, B.; Zelenak, M.; Foldyna, J.; Hloch, S.; Hlavacek, P.; Scucka, J.; Klich, J.; et al. Surface integrity analaysis of abrasive jet-cut surfaces of friction stir welded joints. Int. J. Adv. Manuf. Technol. 2017, 88, 1687-1701. [CrossRef]

30. Mills, B.; Redford, A.H. Machinability of Engineering Materials; Applied Science Ltd.: New York, NY, USA, 1983.

31. Salak, A.; Selecka, M.; Danninger, H. Machinability of Powder Metallurgy Steel; Cambridge International Science Publishing: Cambridge, UK, 2005.

32. Zeng, J. Determination of machinability and abrasive cutting properties in AWJ cutting. In Proceedings of the American WJTA Conference and Expo, Houston, TX, USA, 19-21 August 2007.

33. Wang, J.; Wong, W. Study of abrasive waterjet cutting of metallic coated sheet steels. Int. J. Mach. Tools Manuf. 1999, 39, 855-870. [CrossRef]

34. Wang, J. Predictive depth of jet penetration models for abrasive water jet cutting of alumina ceramics. Int. J. Mech. Sci. 2007, 49, 306-316. [CrossRef]

35. Momber, A.; Kovacevic, R. Principles of Abrasive Water Jet Machining; Springer: London, UK, 1998.

36. Grzesik, W. Advanced Machining Processes of Metallic Materials; Elsevier: London, UK, 2008.

37. Barabas, S.; Florescu, A.; Calefariu, G.; Sarbu, F. Optimization of Abrasive Water Jet Cutting for Carburized Pieces. Adv. Technol. Mater. Res. 2015, 1128, 293-303. [CrossRef]

38. Lebar, A.; Junkar, M. Simulation of abrasive water jet cutting process: Part 1. Unit event approach. J. Model. Sim. Mater. Sci. Eng. 2004, 12, 1159-1170. [CrossRef]

39. Global Water Jet Cutting Machine Industry 2019. Available online: https://www.prnewswire.com/newsreleases/global-waterjet-cutting-machines-industry-300802346.html (accessed on 3 July 2019).

40. Mendez, P.; Barnes, N.; Bell, K.; Borle, S.; Gajapathi, S.; Guest, S.; Izadi, H.; Kamyabi, G.; Wood, G. Welding processes for wear resistant overlays. J. Manuf. Process. 2014, 16, 4-25. [CrossRef]

41. Eremin, E.N.; Losev, A.S. Wear resistance increase of pipeline valves by overlaying welding flux-cored wire. Procedia Eng. 2015, 113, 435-440. [CrossRef]

42. Abson, D.; Power, J. Plant Welds and Joints: Materials Management and Performance Improvement; Woodhead Publishing Limited: Cambridge, UK, 2011.

43. Singh, R. Welding and joining processes. In Applied Welding Engineering; Elsevier: Amsterdam, The Netherlands, 2012.

44. Wang, Q.; Chung, Y. Hardfacing and weld overlay. In Enciclopedia of Tribology; Springer: Berlin, Germany, 2013.

45. Anzehaee, M.; Haeri, M.A. New method to control heat and mass transfer to work piece in a GMAW process. J. Process Control 2012, 22, 1087-1102. [CrossRef]

46. Thomas, D.J. Characterization of aggregate notch cavity formation properties on abrasive water jet cut surfaces. J. Manuf. Process. 2013, 15, 355-363. [CrossRef] 
47. Barabas, S.; Florescu, A. Analysis of bearings behavior with cylindrical rollers with variable center of gravity. MATEC Web Conf. 2017, 94, 02001. [CrossRef]

48. Barabas, B.; Deaconescu, T.; Barabas, S. Reduction of dimensional variability of pieces, resulted in AWJ process, using robust design method. MATEC Web Conf. 2017, 121, 03001. [CrossRef]

(C) 2019 by the authors. Licensee MDPI, Basel, Switzerland. This article is an open access article distributed under the terms and conditions of the Creative Commons Attribution (CC BY) license (http://creativecommons.org/licenses/by/4.0/). 